\title{
Is there a role of prophylactic bilateral internal iliac artery ligation on reducing the bleeding during cesarean hysterectomy in patients with placenta percreta? A retrospective cohort study
}

\author{
Seyhun Sucu' ${ }^{10}$, Hüseyin Çağlayan Özcan ${ }^{1} \mathbb{1}$, Özge Kömürcü Karuserci ${ }^{1}$ (i) ,

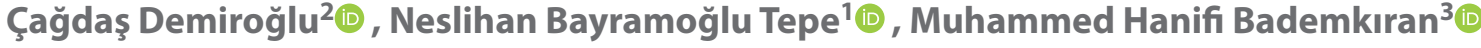 \\ ${ }^{1}$ Deparment of Obstetrics and Gynecology, Gaziantep Univercity, Medical Medicine, Turkey \\ ${ }^{2}$ SANKO University, Gaziantep Gazi Muhtarpaşa Bulvarı, Gaziantep, Turkey \\ ${ }^{3}$ Department of Obstetrics and Gynecology, Health Science University, Gazi Yasargil Education and Research Hospital, \\ Diyarbakır, Turkey
}

\begin{abstract}
Objectives: Our study aims to evaluate the effect of bilateral prophylactic internal iliac artery ligation (IIAL) on bleeding in patients with placenta percreta who undergo cesarean hysterectomy $(\mathrm{CH})$ with the use of blunt dissection technique.

Material and methods: This retrospective cohort study included 96 patients with placenta percreta who underwent planned $\mathrm{CH}$ with using the blunt dissection technique to allow better vesico-uterine dissection at the gynecology and obstetrics unit of a university hospital between the years 2017-2019. We carried out bilateral IIAL before CH in the study group (group 1) while we performed only $\mathrm{CH}$ in the control group (group 2).

Results: Group 1 and Group 2 consisted of 50 and 46 patients; respectively. There was no statistical difference between the two groups as regards to the mean estimated blood loss, the mean transfused blood products, the mean operation time, and the number of complications. In total, 24 patients (25\%) had complications with the finding that the most common one was bladder injury $(16 / 96,16,66 \%)$.

Conclusions: Routine bilateral prophylactic IIAL before $\mathrm{CH}$ in placenta percreta cases does not have a beneficial effect on decreasing the amount of bleeding and the amount blood transfusion
\end{abstract}

Key words: blunt dissection technique; cesarean hysterectomy; internal iliac artery ligation; placenta percreta

Ginekologia Polska 2021; 92, 2: 137-142

\section{INTRODUCTION}

Placenta percreta is an abnormal invasion of the chorionic villi in all uterine layers and sometimes throughout the bladder and rectum [1]. Approximately $5 \%$ of adhesive placental disorders are related to placenta percreta [2]. Despite modern imaging techniques and new surgical methods, placenta percreta remains an important cause of life-threatening condition [3]. Although a hysterectomy is the most preferred surgical procedure [4], bilateral internal iliac artery ligation (IIAL) technique has been performed as a life-saving modality to decrease haemorrhage in obstetrical and pelvic surgeries when other commonly used surgical methods fail [5, 6]. There are only a few studies about using bilateral IIAL during abnormally invasive placenta $[7,8]$ and only placenta percreta surgery [9] which are mostly designed with a limited number of patients. Blunt dissection technique with index finger is a new surgical method to reduce bleeding in the vesico-uterine pouch and to avoid bladder injury during $\mathrm{CH}$ in patients with placenta percreta that invades posterior bladder wall [10].

Our study aims to evaluate the effect of bilateral prophylactic IIAL on bleeding in patients with placenta percreta who undergo $\mathrm{CH}$ with the use of blunt dissection technique.

\section{MATERIAL AND METHODS}

This retrospective cohort study included 96 patients with placenta percreta who underwent $\mathrm{CH}$ at the gynaecology and obstetrics unit of a university hospital between the years 2017-2019. A consent form was obtained from the patients before operations and an approval form was received 


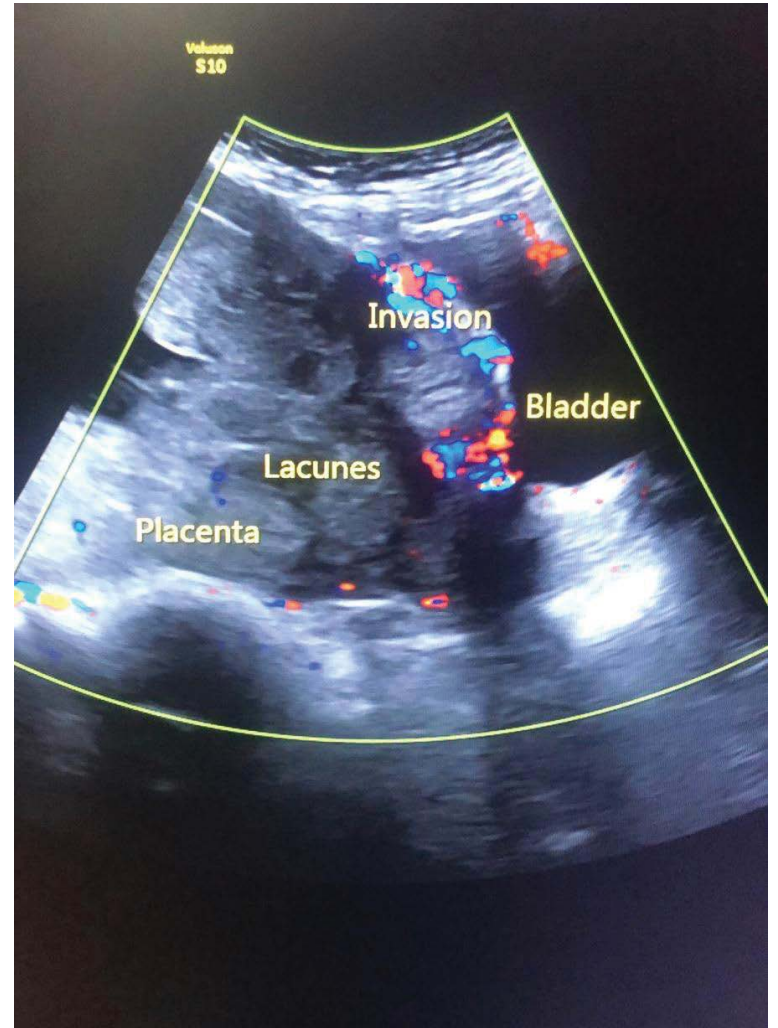

Figure 1. Doppler Ultrasonographic image of placenta percreta

from the University's Ethics Committee (Ethics Approval Number: 2019/44). We diagnosed the patients via grayscale and doppler ultrasonography (USG). Either placental lacunar zone or ambiguous vesico-uterine myometrial borderline in grayscale USG and increased vascularity between placental tissue and bladder in doppler USG were considered ultrasonographic diagnostic criteria (Fig. 1). All patients underwent planned $\mathrm{CH}$ with using the blunt dissection technique at various gestational weeks ranging from 34 to 37 weeks. After delivering the fetus via vertical uterine fundal incision, we filled the bladder with $300 \mathrm{cc}$ saline to better determine the vascularised vesicouterine line and to provide less bleeding in all patients. Blunt dissection method was applied for all patients to make vesico-uterine dissection easier. In the first step of this method, aberrant veins between the low uterine segment and the bladder were skeletonized. In the second step, the bladder was bluntly dissected from the cervix up to the distal cervical point by using the index finger (Fig. 2). Finally, a total hysterectomy was performed. We utilized prophylactic bilateral IIAL by tying the internal iliac artery at $3 \mathrm{~cm}$ distal point of common iliac artery bifurcation with 2-0 silk sutures before $\mathrm{CH}$ in Group 1 patients (Fig. 3) and performed only $\mathrm{CH}$ in Group 2 patients. The same experienced surgical team who had expertise in placenta percreta surgery and were familiar with retroperitoneal anatomy. Patients with hematologic disorders, history of using an- ticoagulant drugs and undergoing emergency $\mathrm{CH}$ were excluded from the study.

Post-operative complications were handled through a multi-disciplinary approach, which included a vascular surgeon and a urologist. We repaired bladder injuries by continued suturing with absorbable synthetic monofilament suture (Monosyn ${ }^{\circledast} 3 / 0$, B-Braun) $3 / 0$ in the mucosa and by interrupted suturing with 2-0 polyglactin 910 (Vicryl ${ }^{\circledR}$; Ethicon) in the serosa and muscular layer. Neocystostomy was employed in only one patient with the ureteral injury. Internal iliac vein injuries were repaired with 5-0 polypropylene suture (PROLENE ; Ethicon). We estimated the blood loss by analyzing the sum of aspirated liquid (blood minus intraoperative saline usage) to the collectors, plus, the weight difference between blood-soaked surgical compress and gauze sponges from the dry ones. The final diagnosis of patients was confirmed by histopathological findings.

\section{Statistical Analysis}

Shapiro-Wilk test was used to understand whether numerical variables were distributed normally. The data that were normally distributed between the groups were analysed through student's t-test while non-normally distributed data were compared via Mann-Whitney $U$ test. Chi-square test was used to analyse the relations between categorical variables. For statistical analyses SPSS 22.0 Windows version was used and a $\mathrm{p}$-value under 0.05 was considered significant.

\section{RESULTS}

In the present study, Group 1 and Group 2 consisted of 50 and 46 patients; respectively. The mean age of the patients in the study was $32.03 \pm 4.96$ (range: $19-44$ years). The mean body mass index $\left(\mathrm{kg} / \mathrm{m}^{2}\right)$ was $27.34 \pm 2.35$ (range: $22-$ -33). The mean parity, gravidity and gestational age (weeks) were $3.09 \pm 1.44$ (range: $1-8$ ), $4.65 \pm 1.80$ (range: $2-11$ ), and $35.7 \pm 1.08$ (range: $34-37$ ); respectively. The comparison of maternal demographic data was shown in Table 1. There was no statistical difference between the two groups concerning age, BMI, parity, previous caesarean section, and gestational age but there was significant difference between the two groups concerning gravidity $(5.04 \pm 1.95$ vs $4.22 \pm 1.53, p=0.024)$. The mean intraoperative estimated blood loss was $1005.73 \pm 518.34 \mathrm{~mL}$ (range: $400-3000$ ). The mean amounts of transfused erythrocyte suspension and fresh frozen plasma were $2.47 \pm 2.01$ units (range: $0-8$ ) and $2.17 \pm 1.83$ units (range: $0-8$ ); respectively. The mean time of operation was $98.65 \pm 31.23$ (range: $50-200$ ) minutes. The mean duration of hospitalization was $4.41 \pm 2.15$ (range: 2-16) days. The comparative data related to preoperative, intraoperative, and postoperative findings were listed in Table 2. There was no statistical difference between 


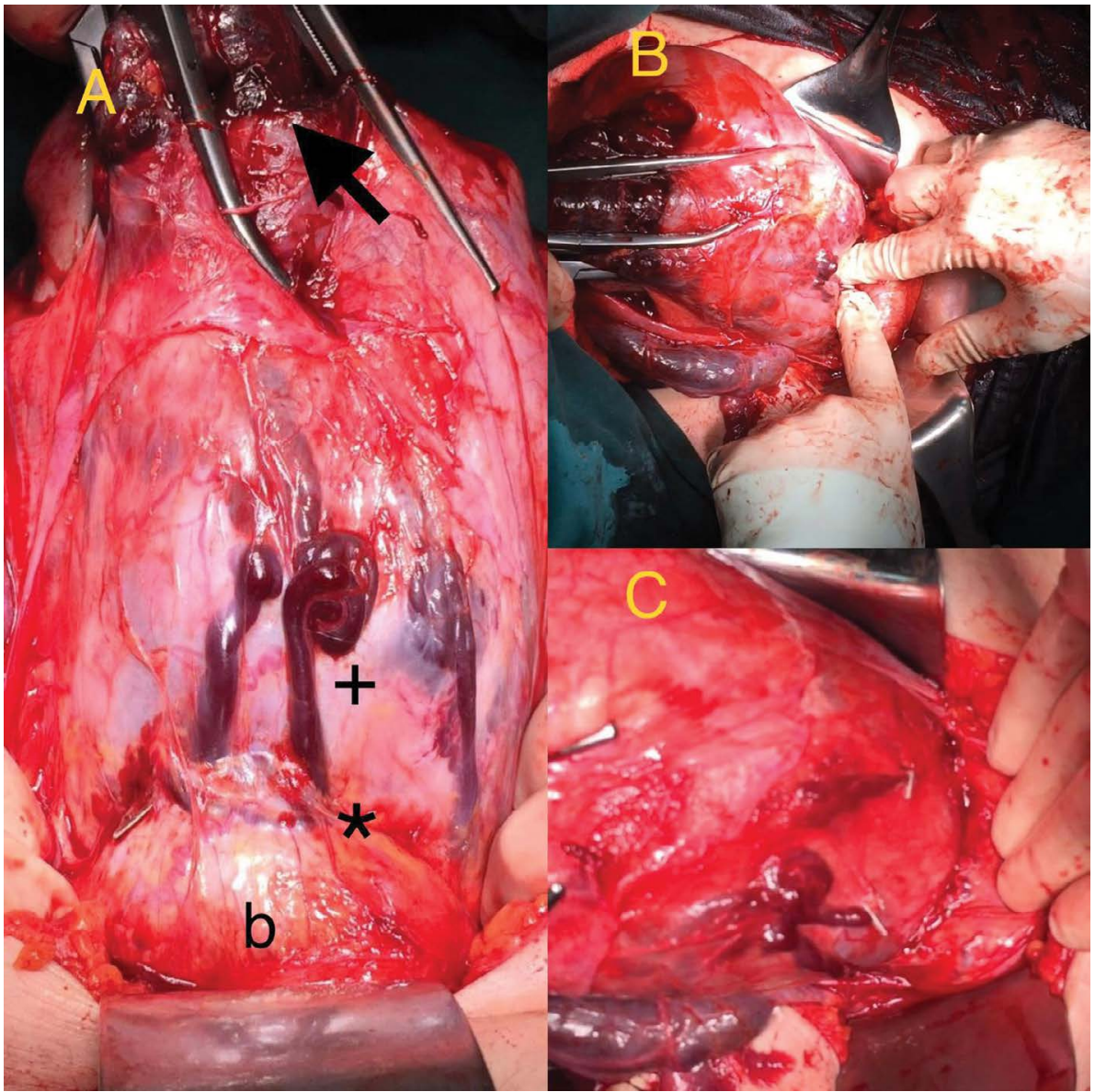

Figure 2. Utilizing blunt dissection technique; A. Asterisk indicates vascularised vesicouterine line. Plus sign indicates lower uterine segment; $b$ indicates filled bladder with $300 \mathrm{~mL}$ saline, Arrow indicates lower part of fundal vertical incision; B. Vesicouetrine dissection with index fingers; C. Dissected bladder from lower uterine segment

the two groups as regards to all parameters which were listed in Table 2. The mean birth weight of neonates was $2732.40 \pm 320.30$ (range: 2000-3500) grams. The mean Apgar scores at $1^{\text {st }}$ and $5^{\text {th }}$ minutes were $7.10 \pm 1.17$ (range: 3-9) and $8.41 \pm 0.88$ (range: 6-10); respectively. In total, 24 patients (25\%) had complications with the finding that the most common one was bladder injury (16/96, 16.66\%). The complication data concerning preoperative, intraoperative and postoperative data were shown in Table 3.

\section{DISCUSSION}

In recent years, the prevalence of patients with placenta percreta has been increasing gradually both in Turkey and throughout the world. It becomes a significant complication since it might threaten mothers' health by causing massive bleeding. In this respect, it is crucial to examine whether prophylactic IIAL might be useful in decreasing massive bleeding during placenta percreta surgery.

Our study found that using prophylactic IIAL has no statistically significant role in reducing the mean blood loss and the mean transfused blood products in placenta percreta patients before $\mathrm{CH}$ with the use of blunt dissection technique. These findings are compatible with those of former studies that examine utilizing prophylactic bilateral IIAL before $\mathrm{CH}$ in patients with abnormally invasive placenta $[7,8]$ and only placenta percreta [9]. Kuhn et al. retrospectively found that bilateral IIAL in patients with placenta percreta undergoing $\mathrm{CH}$ did not significantly decrease the amount of blood loss in 11 patients when compared to 26 patients without bilateral IIAL [9]. The most recent prospective randomized study, which compared 29 patients with prophylactic IIAL before $\mathrm{CH}$ and 28 patients with only $\mathrm{CH}$, suggested that this procedure has no significant impact on reducing intraoperative blood loss [7].

To the best of our knowledge, this study is the most comprehensive regarding the impact of utilizing prophylactic bilateral IIAL before $\mathrm{CH}$ on decreasing the amount of bleeding in patients with placenta percreta.

Bilateral IIAL has a beneficial impact on decreasing postpartum haemorrhage ranging from $40 \%$ to $100 \%$ in the literature [11]. The surgeons' ability and experience play a crucial role. The surgeon has to know retroperitoneal anatomy 


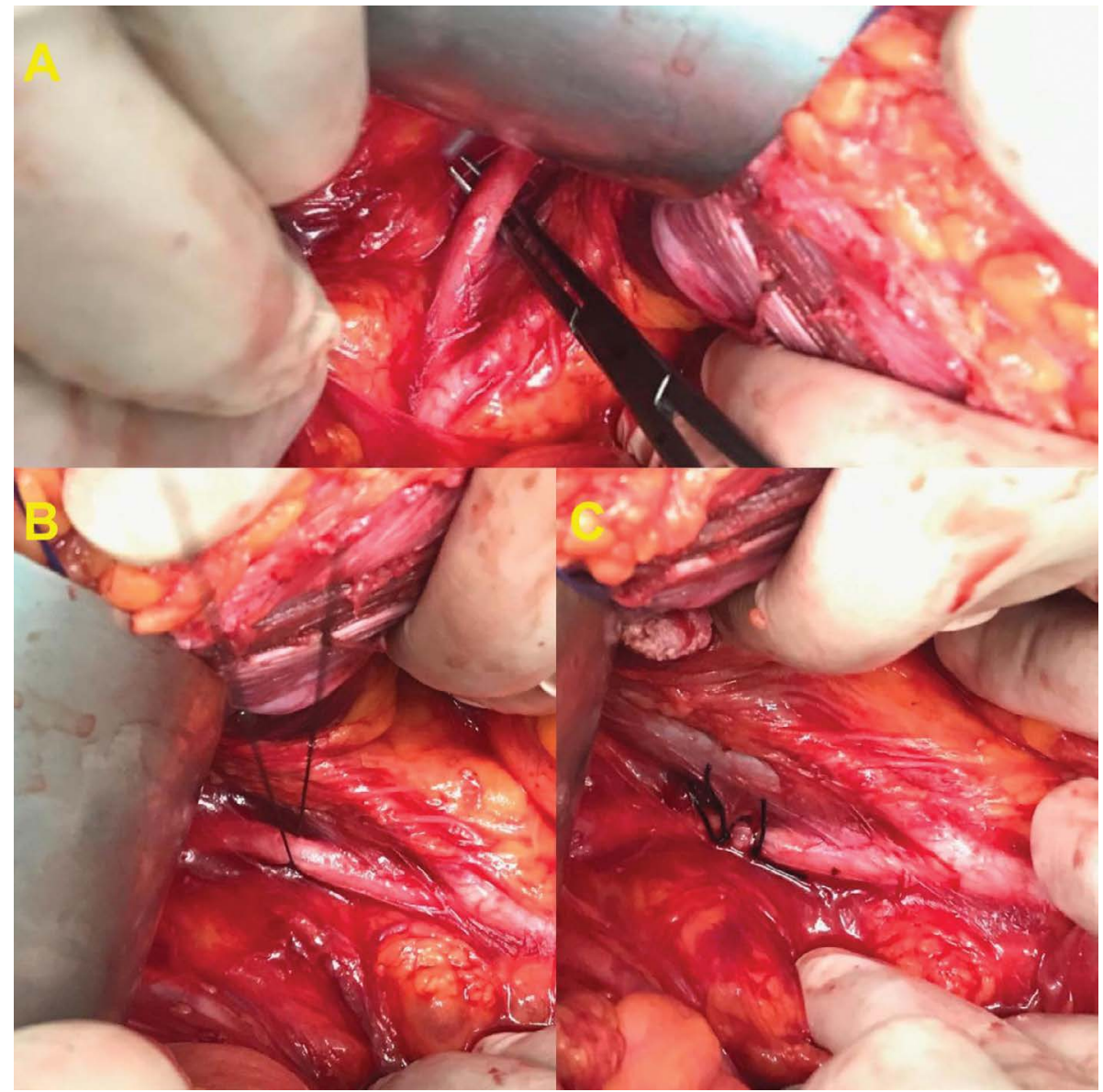

Figure 3. Intraoperative image of internal iliac artery (IIA) ligation; A. Dissection of IIAs sub-region with Wright surgical clamp; B. Holding IIA with 2-0 silk suture; C. Ligation of IIAL from two different points $0.5 \mathrm{~cm}$ apart at $3 \mathrm{~cm}$ distal point of common iliac artery bifurcation

\begin{tabular}{|l|l|l|l|}
\hline \multicolumn{4}{|c|}{ Table 1. Comparison of demographical and obstetrical data } \\
\hline & $\begin{array}{l}\text { GROUP 1 } \\
\text { (n= 50) }\end{array}$ & $\begin{array}{l}\text { GROUP 2 } \\
\text { (n= 46) }\end{array}$ & p \\
\hline Age [years] $†$ & $32.03 \pm 4.96$ & $31.17 \pm 4.5$ & 0.105 \\
\hline BMI [kg/m²] $†$ & $27.53 \pm 2.68$ & $27.14 \pm 1.95$ & 0.421 \\
\hline Gravidity $†$ & $5.04 \pm 1.95$ & $4.22 \pm 1.53$ & $0.024^{*}$ \\
\hline Parity $\dagger$ & $3.36 \pm 1.63$ & $2.8 \pm 1.15$ & 0.103 \\
\hline $\begin{array}{l}\text { Gestational age } \\
\text { [weeks] } †\end{array}$ & $35.54 \pm 1.2$ & $35.87 \pm 0.91$ & 0.149 \\
\hline $\begin{array}{l}\text { Previous } \\
\text { cesarean delivery } \dagger\end{array}$ & $2.72 \pm 1.01$ & $2.5 \pm 0.84$ & 0.281 \\
\hline
\end{tabular}

† mean $\pm \mathrm{SD} ; \mathrm{BMI}$ - body mass index; ${ }^{*} \mathrm{p}<0.05$ value is significant

and must be familiar with potential complications including hypogastric vein injury, ureteral laceration or ligation, external iliac artery ligation, and peripheral nerve injuries [12]. The strengths of our study are the extensive sample size and having experienced surgeons both in retroperitoneal and placenta percreta surgery.

Internal iliac artery balloon occlusion can be used as an alternative to IIAL. However, this procedure is rarely em- ployed only in health centres where experienced interventional radiologists can be found [13]. Moreover, performing an arterial catheter leads to chaotic complications including arterial pseudoaneurysms, acute lower extremity ischemia, reperfusion injury, and even arterial rupture [14-19]. The studies related to internal iliac artery balloon occlusion could not demonstrate any significant decrease in blood loss results $[14,20]$.

Although the bilateral IIAL procedure decreases the amount of bleeding in women's genital system, it cannot eliminate it [21]. Some studies stated that collateral circulation between internal and external iliac arteries contributes to extensive bleeding $[22,23]$. Several studies demonstrated that intra-operative mean blood loss is less than the mean value reported in the literature by temporarily occluding common iliac arteries or aorta through the femoral artery $[13,24,25]$. Therefore, these procedures may have a promising potential on decreasing the amount of bleeding.

The main limitation of our study is designing in a retrospective manner. Another limitation may be the overestimation of complications due to the high referral rate to our third-degree hospital, which has the biggest obstetrical 
Table 2. Comparison of preoperative, intraoperative and postoperative data

\begin{tabular}{|c|c|c|c|}
\hline & $\begin{array}{l}\text { GROUP } 1 \\
\text { (n: 50) }\end{array}$ & $\begin{array}{l}\text { GROUP } 2 \\
(n: 46)\end{array}$ & $\mathbf{p}$ \\
\hline $\begin{array}{l}\text { Preoperative } \mathrm{Hb} \\
{[\mathrm{g} / \mathrm{dL}] \dagger}\end{array}$ & $11.43 \pm 1.35$ & $11.51 \pm 1.11$ & 0.738 \\
\hline $\begin{array}{l}\text { Postoperative } \mathrm{Hb} \\
{[\mathrm{g} / \mathrm{dl} \mathrm{L}] \dagger}\end{array}$ & $10.39 \pm 1.35$ & $9.9 \pm 1.17$ & 0.064 \\
\hline $\begin{array}{l}\text { Intraoperative EBL } \\
{[\mathrm{mL}] \dagger}\end{array}$ & $993 \pm 493.43$ & $1019.57 \pm 549.29$ & 0.862 \\
\hline $\begin{array}{l}\text { Intraoperative units } \\
\text { of RBCs transfused } \dagger\end{array}$ & $2.14 \pm 1.79$ & $2.82 \pm 2.18$ & 0.102 \\
\hline $\begin{array}{l}\text { Intraoperative units } \\
\text { of FFP transfused } \dagger\end{array}$ & $1.88 \pm 1.56$ & $2.47 \pm 2.05$ & 0.151 \\
\hline $\begin{array}{l}\text { Intraoperative } \\
\text { fibrinogens } \\
{[1 \text { gr/flacon] }]}\end{array}$ & $0.2 \pm 0.57$ & $0.3 \pm 0.73$ & 0.587 \\
\hline $\begin{array}{l}\text { Maternal ICU } \\
\text { admission } \neq\end{array}$ & $7(14 \%)$ & $10(21.7 \%)$ & 0.321 \\
\hline $\begin{array}{l}\text { Operation time } \\
\text { [minutes] } \dagger\end{array}$ & $101.4 \pm 29.95$ & $95.65 \pm 32.64$ & 0.190 \\
\hline $\begin{array}{l}\text { Duration of } \\
\text { hospitalization } \\
\text { [days] } \dagger\end{array}$ & $4.26 \pm 2.11$ & $4.57 \pm 2.21$ & 0.473 \\
\hline $\begin{array}{l}\text { The number of } \\
\text { complication } \neq\end{array}$ & $12(24 \%)$ & 12 (26.1\%) & 0.814 \\
\hline
\end{tabular}

† mean $\pm \mathrm{SD} ; \neq \mathrm{n}(\%) ; \mathrm{EBL}$ — estimated blood loss; $\mathrm{g} / \mathrm{dL}$ - gram/decilitre; ICU — intensive care unit; RBCs - red blood cells, FFP — fresh frozen plasma; $\mathrm{Hb}-$ haemoglobin; ${ }^{*} \mathrm{p}<0.05$ value is significant

\begin{tabular}{|c|c|c|}
\hline Complications & Group 1 (n: 50) & Group 2 (n: 46) \\
\hline \multicolumn{3}{|l|}{ İntraoperative } \\
\hline Bladder injury $\neq$ & $9(18 \%)$ & $7(15.2 \%)$ \\
\hline Urethral injury $\ddagger$ & 0 & $1(2.17 \%)$ \\
\hline Internal iliac vein injury $\ddagger$ & $2(4 \%)$ & 0 \\
\hline Internal iliac artery injury $\neq$ & $1(2 \%)$ & 0 \\
\hline \multicolumn{3}{|l|}{ Postoperative } \\
\hline $\begin{array}{l}\text { Pelvic hematoma leading to } \\
\text { re-laparotomy } \neq\end{array}$ & $1(2 \%)$ & $2(4.34 \%)$ \\
\hline Ileusł & 0 & $1(2.17 \%)$ \\
\hline
\end{tabular}

$\ddagger \mathrm{n}(\%)$

capacity in the southeast region of Turkey. The complications were classified as intra-operative (bladder injury, ureteral injury and vascular injury) and post-operative (ileus and post-operative hematoma) in our study.

\section{Bladder injury was the most common complication}

Bladder injury is more common in patients that have a hysterectomy due to placental invasion than those pa- tients that have an elective hysterectomy because of various gynaecological reasons [26, 27]. In literature, the incidence of genitourinary injuries related to abnormally placental invasion is up to $29 \%$ [26, 28]. Nieto-Calvache et al. [29] demonstrated that the incidence of bladder injury in patients with abnormal placental invasion is $23 \%$. However, this incidence was lower in our study when compared to the above-mentioned studies $(16 / 96, \% 16,6)$. We attribute the low rate of bladder injury to the use of blunt dissection technique in all patients.

\section{CONCLUSIONS}

In conclusion, routine bilateral prophylactic IIAL before $\mathrm{CH}$ in placenta percreta cases does not have beneficial effect on decreasing the amount of bleeding and the amount of blood transfusion. Further prospective studies with more extended sample size are needed for more accurate outcomes.

\section{Conflicts of interest}

We declare that there are no conflicts of interest in connection with this article.

\section{Funding}

There is no funding regarding this article.

\section{Acknowledgement}

The authors would like to thank Tanyeli Güneyligil KAZAZ for statistical analysis.

\section{REFERENCES}

1. Garmi G, Salim R. Epidemiology, etiology, diagnosis, and management of placenta accreta. Obstet Gynecol Int. 2012; 2012: 873929, doi: 10.1155/2012/873929, indexed in Pubmed: 22645616.

2. Konijeti R, Rajfer J, Askari A. Placenta percreta and the urologist. Rev Urol. 2009; 11(3): 173-176, indexed in Pubmed: 19918343.

3. Committee on Obstetric Practice. Committee opinion no. 529 placenta accreta. Obstet Gynecol. 2012; 120(1): 207-211, doi: 10.1097/AOG.0b013e318262e340, indexed in Pubmed: 22914422.

4. Committee on Practice Bulletins-Obstetrics. Practice Bulletin No. 183 Postpartum Hemorrhage. Obstet Gynecol. 2017; 130(4): e168-e186, doi: 10.1097/AOG.0000000000002351, indexed in Pubmed: 28937571.

5. Paraskevaides E, Noelke L, Afrasiabi M. Internal iliac artery ligation (IIAL) in obstetrics and gynaecology. Eur J Obstet Gynecol Reprod Biol. 1993; 52(1): 73-75, doi: 10.1016/0028-2243(93)90229-6, indexed in Pubmed: 8119480.

6. Kidney DD, Nguyen AM, Ahdoot D, et al. Prophylactic perioperative hypogastric artery balloon occlusion in abnormal placentation. AJR Am J Roentgenol. 2001;176(6): 1521-1524, doi: 10.2214/ajr.176.6.1761521, indexed in Pubmed: 11373225.

7. Hussein AM, Dakhly DM, Raslan AN, et al. The role of prophylactic internal iliac artery ligation in abnormally invasive placenta undergoing caesarean hysterectomy: a randomized control trial. J Matern Fetal Neonatal Med. 2019; 32(20): 3386-3392, doi: 10.1080/14767058.2018.1463986, indexed in Pubmed: 29635951.

8. Iwata A, Murayama $Y$, Itakura A, et al. Limitations of internal iliac artery ligation for the reduction of intraoperative hemorrhage during cesarean hysterectomy in cases of placenta previa accreta. J Obstet Gynaecol Res. 2010; 36(2): 254-259, doi: 10.1111/j.1447-0756.2009.01 157.x, indexed in Pubmed: 20492374. 
9. Kuhn T, Martimucci K, Al-Khan A, et al. Prophylactic Hypogastric Artery Ligation during Placenta Percreta Surgery: A Retrospective Cohort Study. AJP Rep. 2018; 8(2): e142-e145, doi: 10.1055/s-0038-1666793, indexed in Pubmed: 29977660.

10. Özcan HÇ, Uğur MG, Sucu S, et al. Blunt dissection technique with finger and vessel skeletonization in the posterior vesical wall for abnormally invasive placenta previa. J Matern Fetal Neonatal Med. 2019; 33(14): 2441-2444, doi: 10.1080/14767058.2018.1554043.

11. Joshi VM, Otiv SR, Majumder $R$, et al. Internal iliac artery ligation for arresting postpartum haemorrhage. BJOG. 2007; 114(3): 356-361, doi: 10.1111/j.1471-0528.2006.01235.x, indexed in Pubmed: 17261120.

12. Fargeaudou $Y$, Morel $O$, Soyer $P$, et al. Persistent postpartum haemorrhage after failed arterial ligation: value of pelvic embolisation. Eur Radiol. 2010; 20(7): 1777-1785, doi: 10.1007/s00330-010-1713-y, indexed in Pubmed: 20309561.

13. Shih JC, Liu KL, Shyu MK. Temporary balloon occlusion of the common iliac artery: new approach to bleeding control during cesarean hysterectomy for placenta percreta. Am J Obstet Gynecol. 2005; 193(5): 17561758, doi: 10.1016/j.ajog.2005.08.033, indexed in Pubmed: 16260225.

14. Shrivastava $V$, Nageotte $M$, Major $C$, et al. Case-control comparison of cesarean hysterectomy with and without prophylactic placement of intravascular balloon catheters for placenta accreta. Am J Obstet Gynecol. 2007; 197(4): 402.e1-402.e5, doi: 10.1016/j.ajog.2007.08.001, indexed in Pubmed: 17904978.

15. Dilauro MD, Dason S, Athreya S. Prophylactic balloon occlusion of internal iliac arteries in women with placenta accreta: literature review and analysis. Clin Radiol. 2012; 67(6): 515-520, doi: 10.1016/j. crad.2011.10.031, indexed in Pubmed: 22218410.

16. Peng $Q$, Zhang W. Rupture of multiple pseudoaneurysms as a rare complication of common iliac artery balloon occlusion in a patient with placenta accreta: A case report and review of literature. Medicine (Baltimore). 2018; 97(12): e9896, doi: 10.1097/MD.0000000000009896, indexed in Pubmed: 29561462

17. Greer JW, Flanagan C, Bhavaraju A, et al. Right external iliac artery thrombus following the use of resuscitative endovascular balloon occlusion of the aorta for placenta accreta. J Surg Case Rep. 2018; 2018(11): rjy313, doi: 10.1093/jscr/rjy313, indexed in Pubmed: 30443322.

18. Bishop S, Butler K, Monaghan S, et al. Multiple complications following the use of prophylactic internal iliac artery balloon catheterisation in a patient with placenta percreta. Int J Obstet Anesth. 2011; 20(1): 70-73, doi: 10.1016/j.ijoa.2010.09.012, indexed in Pubmed: 21168325.
19. Papillon-Smith J, Singh SS, Ziegler C. Internal Iliac Artery Rupture Caused by Endovascular Balloons in a Woman with Placenta Percreta. J Obstet Gynaecol Can. 2016; 38(11): 1024-1027, doi: 10.1016/j.jogc.2016.09.001, indexed in Pubmed: 27969555.

20. Bodner LJ, Nosher JL, Gribbin C, et al. Balloon-assisted occlusion of the internal iliac arteries in patients with placenta accreta/percreta. Cardiovasc Intervent Radiol. 2006; 29(3): 354-361, doi: 10.1007/s00270005-0023-2, indexed in Pubmed: 16502171.

21. Sziller I, Hupuczi P, Papp Z. Hypogastric artery ligation for severe hemorrhage in obstetric patients. J Perinat Med. 2007; 35(3): 187-192, doi: 10.1515/JPM.2007.049, indexed in Pubmed: 17480145.

22. Hansch E, Chitkara U, McAlpine J, et al. Pelvic arterial embolization for control of obstetric hemorrhage: a five-year experience. Am J Obstet Gynecol. 1999; 180(6 Pt 1): 1454-1460, doi: 10.1016/s0002-9378(99)700360 , indexed in Pubmed: 10368488.

23. Clark SL, Phelan JP,Yeh SY, et al. Hypogastric artery ligation for obstetric hemorrhage. Obstet Gynecol. 1985; 66(3):353-356, indexed in Pubmed: 3875064.

24. Panici PB, Anceschi M, Borgia ML, et al. Fetal Maternal Risk Group. Intraoperative aorta balloon occlusion: fertility preservation in patients with placenta previa accreta/increta. J Matern Fetal Neonatal Med. 2012; 25(12): 2512-2516, doi: 10.3109/14767058.2012.712566, indexed in Pubmed: 22992070.

25. Duan $\mathrm{XH}$, Wang $\mathrm{YL}$, Han $\mathrm{XW}$, et al. Caesarean section combined with temporary aortic balloon occlusion followed by uterine artery embolisation for the management of placenta accreta. Clin Radiol. 2015; 70(9): 932-937, doi: 10.1016/j.crad.2015.03.008.

26. Tam Tam KB, Dozier J, Martin JN. Approaches to reduce urinary tract injury during management of placenta accreta, increta, and percreta: a systematic review. J Matern Fetal Neonatal Med. 2012; 25(4): 329-334, doi: 10.3109/14767058.2011.576720, indexed in Pubmed: 23003574.

27. Vakili B, Chesson RR, Kyle BL, et al. The incidence of urinary tract injury during hysterectomy: a prospective analysis based on universal cystoscopy. Am J Obstet Gynecol. 2005; 192(5): 1599-1604, doi: 10.1016/j. ajog.2004.11.016, indexed in Pubmed: 15902164.

28. Norris BL, Everaerts W, Posma E, et al. The urologist's role in multidisciplinary management of placenta percreta. BJU Int. 2016; 117(6): 961-965, doi: 10.1111/bju.13332, indexed in Pubmed: 26389985.

29. Nieto-Calvache AJ, López-Girón MC, Messa-Bryon A, et al. Urinary tract injuries during treatment of patients with morbidly adherent placenta. J Matern Fetal Neonatal Med. 2019 [Epub ahead of print]: 1-7, doi: 10.1080/14767058.2019.1678135, indexed in Pubmed: 31631730. 